\title{
Design, Implementation and Evaluation of a Learning Object that Supports the Mathematics Learning in Children with Autism Spectrum Disorders
}

\author{
Roberto Munoz, Carlos Becerra, René Noël, Matías Camblor \\ Universidad de Valparaíso, Facultad de Ingeniería, \\ Valparaíso, Chile, 2340000 \\ \{roberto.munoz, carlos.becerra, rene.noel\}@uv.cl, matias.camblor@alumnos.uv.cl
}

and

Thiago S. Barcelos

Instituto Federal de Educação, Ciência e Tecnologia de São Paulo, Laboratório de Tecnologias

para Interação,

Guarulhos, Brasil, 07115-000

tsbarcelos@ifsp.edu.br

and

Sandra V. Kreisel

Universidad de Valparaíso, Facultad de Medicina,

Valparaíso, Chile, 2603015

sandra.kreisel@uv.cl

and

\section{Rodolfo Villarroel}

Pontificia Universidad Católica de Valparaíso, Facultad de Ingeniería,

Valparaíso, Chile, 2362807

rodolfo.villarroel@pucv.cl

\begin{abstract}
Information technologies have been widely used for entertainment and learning purposes by children with Autism Spectrum Disorders (ASD). Nonetheless, learning objects aiming at specific skills development in children with ASD require both a well bounded learning domain and a user-centered design process, considering skill levels of the users and the local geographical context and language.

"Proyect@ Matemáticas" is a multi-touch based app designed for developing pre-calculus and functional mathematical skills in children with ASD, according to the Chilean regulations of learning goals for children with special educational necessities. This paper presents the Usercentered design process conducted in order to develop the learning object, which included the evaluation by 15 experts in special educational needs, testing by 10 ASD-diagnosed children with different functional levels, and a multidisciplinary development team that also included a graphic designer diagnosed with ASD of high functionality.

The development process yields to a validated learning object in terms of interactivity, design, engagement and usability, from the point of view of the experts, and successful usage tests with ASD diagnosed children in terms of performance and achievement of learning outcomes. The application is currently available for download in the Google Play store for free, and currently has more than 15,000 downloads and an average rating of 4.2 out of 5 points.
\end{abstract}


Keywords: Autism Spectrum Disorders, Mathematics, Learning Object, Multitouch Application.

\section{INTRODUCTION}

Autism Spectrum Disorder (ASD) is a name for a group of neurodevelopmental conditions that are characterized by some degree of impairment in social interaction, verbal and non-verbal communication, and difficulty in symbolic capacity and repetitive behaviors [1]. This triad is accompanied by other characteristics, such as resistance to change, stereotypical behaviors, and a need for predictability and extreme clarity [2].

Those with ASD process information differently, which is directly linked to a different way of conceptualizing. At the same time, it should be noted that, although ASD is not a disease, it is a permanent condition of neuronal development. Hence, the support of multidisciplinary teams is necessary to stimulate the future integration and independency levels of an individual with such condition [3]. It is for this reason that the level of needed support will vary from person to person, in accordance with his or her characteristics, the level of support being classified into three levels: "requiring support", "requiring substantial support," or "requiring very substantial support" [4].

Currently, the number of children diagnosed with ASD continues rising, which reminds us of the necessities of this community [5]. The prevalence of ASD in recent years reports a frequency close to $1.4 \%$ of the worldwide population, with similar sampling estimates in children and adults [6]. In the majority of cases, the characteristics of a person with ASD continue for the rest of his or her life; however, the people who possess this disorder can better their condition with the aid of multidisciplinary teams [7].

In Chile, there is no specific curricular framework for the teaching of mathematics that determines learning and contents to address special education needs. This is due to decrees regulating the administrative area, which causes professionals and institutions, those responsible for teaching these children mathematical setting, to restructure the existing curricular framework [8] and readapt it to the special needs of these children, creating separated groups based on mathematical skill levels.

One of the challenges surrounding the development of learning objects for people with special needs is in the design of the user interface. Among other considerations, it is necessary to understand the cognitive and functioning levels of users, as well as local aspects associated with culture and language. A systematic approach to address this problem is the design methodology centered on the user, otherwise known as User-Centered Design (UCD). It is defined as a philosophy that puts the user in the center of the design process, taking into account the characteristics, needs, and desires of the people that will use these products [9]. Its principal strategy is the usage of research techniques and methods that aim to bring the user to the center of the design process [10]. This is done with the goal of creating products that are appropriate and useful, taking into account good practices that ensure usability [10]. UCD stems from the field of Human-Computer Interaction as a support methodology for developers and designers, generating software and hardware that adequately meets the needs of users. The principles of UCD are: 1) early focus on users and their tasks, 2) evaluation and measurement of product use, 3) interactive design [11], [12]. It is worth mentioning that this approach has been previously applied by the authors in the development of learning objects with similar characteristics to the one presented in this article, such as "Proyect@ Emociones" [5] and "Proyect@ Habilidades" [13].

Technological tools can be of great utility in approaching ASD, always assuming they are complementary [14]. Information and Communications Technology (ICT), has become an instrumental aid well accepted within the therapeutic approach [15] given the significant advancement it has made in the last few years. While the progress of automated tools and systems that assist the development of skills exist around the world [16], [17], [18], [19] in Chile these cannot be utilized in the best manner, since factors such as language and idiosyncrasies unique to each country greatly hinder the task that they seek to develop.

For the reasons given above, a Learning Object (LO) [20] for multi-touch devices was developed aimed at supporting professionals (speech pathologists, special-education educators, psychologists) involved with the development of cognitive skills in children with ASD. The LO proposal is focused on functional mathematics and pre-calculus according to the Chilean educational system. For this, it was necessary to work in educational institutions where the needs for children with ASD could be identified and, subsequently, the usability and interaction with the final user could be evaluated.

The result, in terms of its functionality, was a LO that permits, through leisure activities, pre-calculus work (forms, figures, addition, subtraction, etc.) and functional mathematics (use of money, problems involving money, etc.). On the other hand, the LO proposal, as of January 2017, has around 15,000 downloads on the mass diffusion platform Google Play. 


\section{Technologies as Support to Autism SPECTRUM Disorders}

The scope of new technologies regarding children with ASD has been increasing due to a great interest in this area, which has been evidenced by previous research [16], [18]. Currently, we can find a great variety of means and resources for attending the special needs of these children. However, these often lack scientific validation or are not aligned with the standards of the educational curriculum [5]. In this context, ICTs are still a promising alternative to improve the quality of life of these children and, in some cases, enable access to a defined school curriculum, communication [21], or be a means of facilitation for learning [22], social and labor integration [15].

The use of technology in the field of inclusive education has not only brought about new opportunities, but has also lowered risks, such as digital exclusion and curricular decontextualization. This digital gap is due to diverse motives, but mainly due to the absence of specific policies involving ICTs and special education needs, whether from lack of economic support or appropriate tools.

ICTs are very attractive tools and a potential resource for people with special needs and especially those with ASD, which include the following characteristics [23]:

- Offer an environment and controllable situation, with predictable responses. They present multisensory stimulation, including visual stimulation

- Their capacity for motivation and reinforcement is very high, they favor attention and reduce frustration before errors

- They favor or enable autonomous work and the development of auto-control skills

- They are flexible and adaptable to the learning pace of each individual

- They increase or improve the communication skills (expressive and receptive). They improve fine motor skills and diminish repetitive behaviors. They improve social interaction and academic skills.

\section{Mathematics Education in ChILdREn With AUTISM SPECTRUM Disorders}

In order to introduce mathematics topics to children within the Autism Spectrum, it must be pointed out that currently in Chile there is not a specific curricular framework for mathematics that determines learning strategies and contents to approach special education. The main reason for this is that the Chilean public administration regulates only the administrative aspects of special education, which means that the professionals and centers charged with the education of these children in mathematics must restructure the existing curricular framework [24] by themselves and adapt it to the special needs of these children, creating groups separated by mathematical skills developed by each child.

In the field of mathematics education, better methods are being applied in the teaching of students with Special Education Needs. One of the best learning practices for children with ASD is the use of the concrete-representationalabstract sequence. Instruction at the concrete level implies the use of objects as a manipulation device to promote the conceptual comprehension of a mathematical skill involved in each activity. Those students that dominate the concrete level of instruction move on to the representational level; this level of instruction often includes the use of drawings and/or figures. Typical activities with the best results are those that present a written number that is shown beside a figure or drawing of a quantity representative of that number. The representational level permits children to concentrate on the most important concept, which is determining which function to apply to the numbers, addition or subtraction [25].

In the pursuit of developing math skills in children with ASD, focused principally on functional mathematics, we find that the Curricular Guidelines for Mathematics defined by the Chilean Education Ministry (Ministerio de Educación de Chile) [24] specifies certain skills necessary for the development of mathematical reasoning:

- Solving problems: challenges in which the student must achieve a solution to a given situation; they experiment, choose, or invent, apply different strategies, compare different means of reaching a solution and evaluate the responses obtained and their pertinence [26].

- Arguing: the goal is, principally, that students communicate their reasoning or actions toward resolving a problem.

- Modelling: the objective of this ability is that the student builds a simplified and abstract version of a system, usually more complex, but that he or she identifies key patterns and then expresses them through a mathematical language.

- Representing: it is hoped that students learn to use pictorial representations such as diagrams, schemes, and graphs in order to communicate quantities, operations, and relations, and that later they understand and use 
symbolic language and appropriate vocabulary of the discipline.

\section{Related Work}

Currently in Chile, ICT barely forms part of the therapeutic strategies for the promotion of cognitive abilities of patients with ASD. This happens mainly due to a lack of tools developed for the Chilean public. This is a disadvantage, as applications have been generated outside of national scope, and therefore developed to be used by the user of the regions in which they were generated, representing their cultures and customs, which in most cases are very different from our own idiosyncrasies. This is especially noticed when children receive appropriate services and/or therapies in their local environment.

Table 1 presents a comparison of 7 applications oriented toward mathematics learning for children with ASD. The applications were found by querying the search engine of Google Play Store with the search string Mathematics + Autism in April 2016.

Table 1: Comparison between applications

\begin{tabular}{cccccc}
\hline Application & $\begin{array}{c}\text { Operative } \\
\text { System }\end{array}$ & Description & $\begin{array}{c}\text { Main } \\
\text { characteristics }\end{array}$ & Free & Language \\
\hline Learn with Rufus: Numbers & Android & Learning Activities & Pre-calculus & No & English, Spanish \\
\hline Touch-Numbers & Android & Learning Activities & Pre-calculus & No & $\begin{array}{c}\text { English, Spanish, } \\
\text { French }\end{array}$ \\
\hline Number Sequence-Autism Series & Android & Learning Activities & Pre-calculus & Yes & English \\
\hline Show me Numbers-Autism Series & Android & Learning Activities & Pre-calculus & Yes & English \\
\hline 123 Order - Lite Autism Series & Android & Learning Activities & Pre-calculus & Yes & English \\
\hline Add Me - Lite Autism Series & Android & Learning Activities & Pre-calculus & Yes & English \\
\hline $\begin{array}{c}\text { Number Find - Lite Autism } \\
\text { Series }\end{array}$ & Android & Learning Activities & Pre-calculus & Yes & English \\
\hline
\end{tabular}

From the revised applications, none of them allow for functional mathematics work. In addition, they focus on precalculus and are mainly in English. On the other hand, the only two applications available in the Spanish language are not free (must be purchased).

\section{Methodology}

We choose User-Centered Design (UCD) methodology [27] for the development of the project, due to its wide acceptance as a way of elicit and address the real needs of its users [28]. On the other hand, the team had previous experience in projects using this methodology to develop applications for children within the ASD.

In the following sections, we describe how each stage of the methodology is contextualized to this work.

\subsection{Stage 1: Definition of target users and requirements}

For this project, a group of children with ASD between 8 and 11 years old-attending a Chilean special-education school-were selected along with teachers, therapists, and parents, in order to improve integration with other children with ASD, and to facilitate the learning of disciplines. In this stage, the requirements were obtained based on:

- Bibliographical review on the subject;

- Fieldwork with children with ASD, through participative observation of a pilot program to increase the subjective experiences of observers during the process;

- Focus Groups with parents and/or guardians of selected children.

\subsection{Stage 2: Analysis}

This stage was based on the following activities [10]:

- Exposure to the group of researchers and specialists of the main problem that is being solved.

- Registrations, improvement of ideas and selection of the most viable ones.

- During these sessions, graphic scripts or storyboards were created, using them to clarify how the system is applied in a real-world scenario. 


\subsection{Stage 3: Design}

At this stage, a set of interfaces associated with the scenarios of the use of tools that reproduce the actual behaviors of children with ASD were created.

The prototypes of the interfaces are built using paper sketches [29] and, after being approved by the team, a step to the final interface is realized. Some examples are presented in Figure 1.
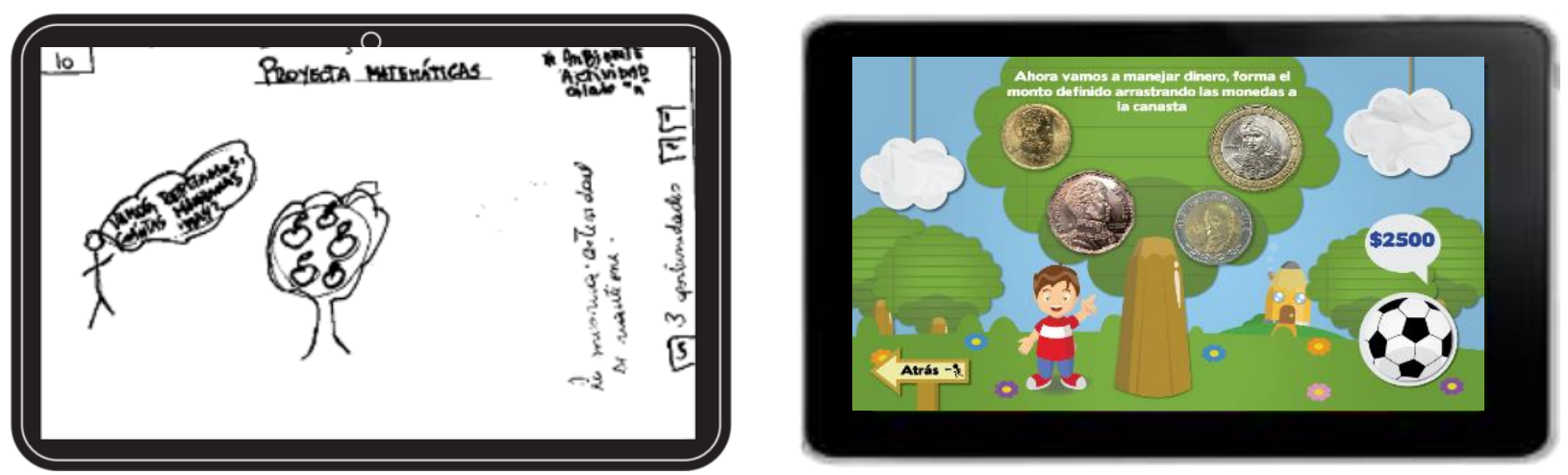

Figure 1: Paper Prototype and Final Interface of Proyect@ Matemáticas

One relevant aspect is that a graphic designer diagnosed with high-functioning ASD was present within the development team, being in charge of the design of the graphical interface of the LO.

\subsection{Stage 4: Evaluation}

An evaluation of the first functional prototype was performed. The objective was to assure that the people involved in this project (children with ASD, parents, and therapists) could successfully use the product. The details of this stage are presented in section 8 .

\section{Software Architecture of Proyect@ Matemáticas}

The application Proyect@Matemáticas was developed for devices with the Android Operating System, and was implemented using an Android system architectural base and the Model View Controller (MVC) as the architectural pattern. This type of architecture has the advantage of providing access to the lower layers of the operating system through the use of libraries; in this way the developer does not have to program the necessary functionalities at a low level so that an application can make use of the components of hardware devices. The main modules of Mathematics Project are presented in Figure 2.

Next, the details of the component view are specified:

- Mathematics Project: This is the principal component that packages the entire application.

- Interface: In this module, the menu of system interaction activities is found.

- Menu Activities: Presents the interface for accessing the application activities.

- Activities: The application activities separated into 2 groups:

- Calculus Activities: Activities related to pre-calculus with basic notions are presented

- Functional Mathematics Activities: Activities related to functional mathematics using monetary units are presented

- Database: In this module, user data and an image repository are obtained

- Repository: Permits access to necessary images to realize distinct activities

- Users: Permits the storage of users' data and results 


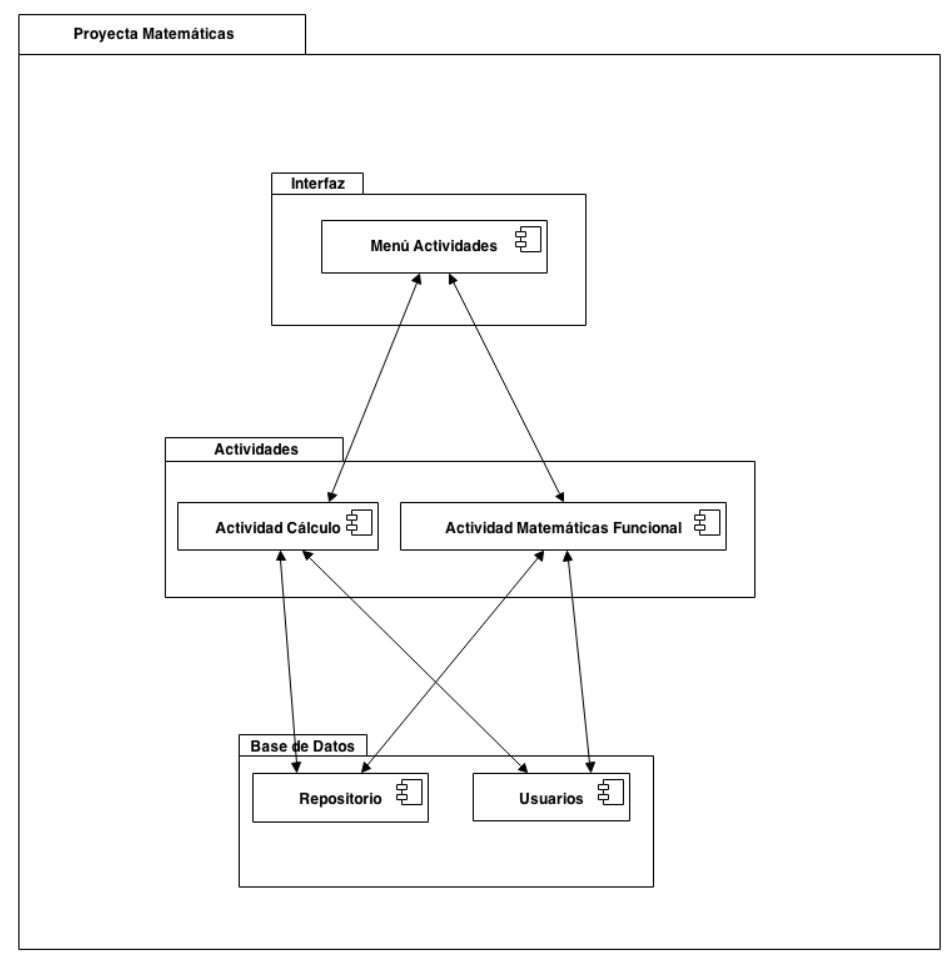

Figure 2: Software Architecture of Proyect@ Matemáticas

The navigation diagram (see Figure 3) represents the different menus and activities that the user can access within the application and that are directly related with the architecture of the described software.

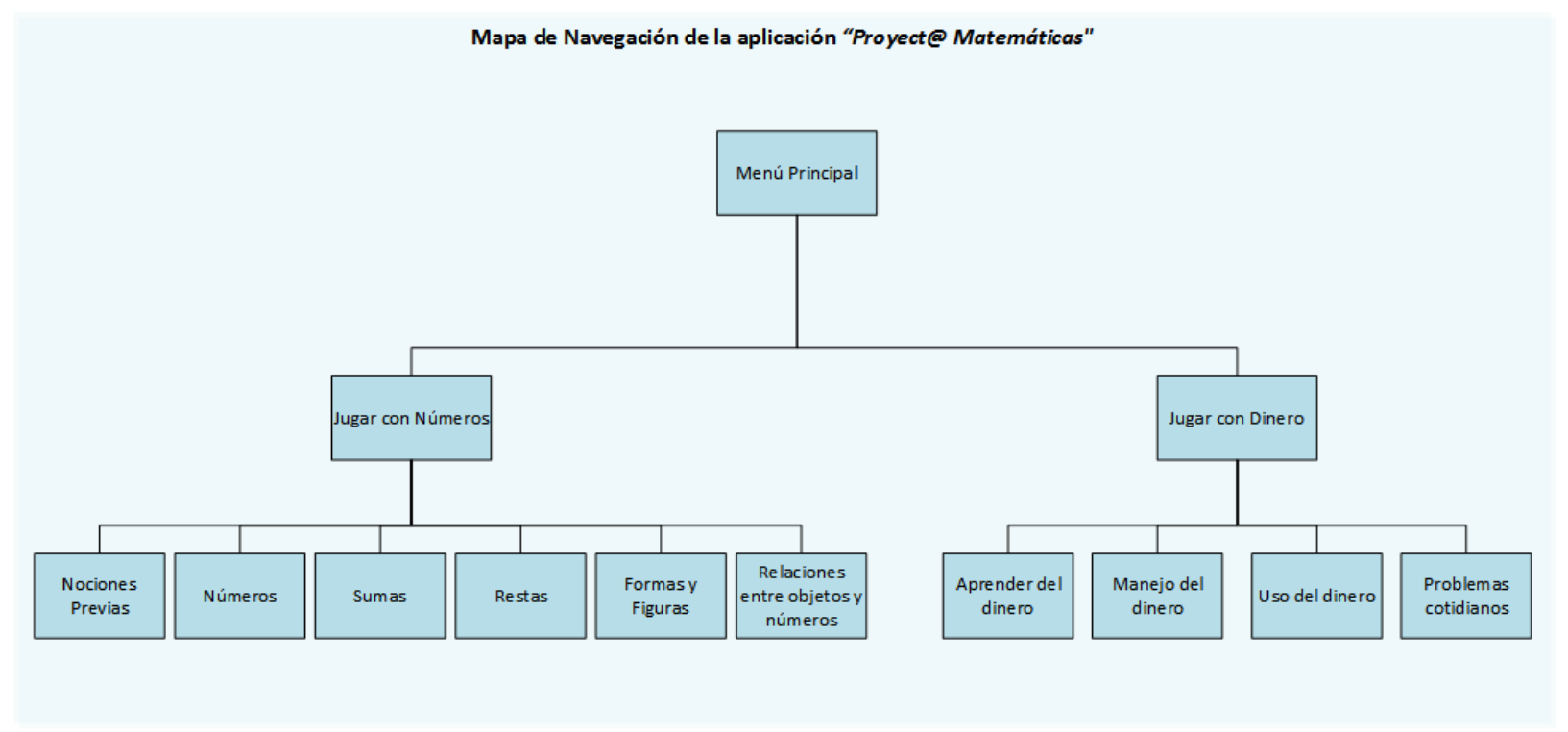

Figure 3: Navigational Diagram of Proyect@ Matemáticas

\section{Learning Object Proyect@ Matemática}

After 2 cycles of the proposed methodology, the pre-calculus interface of the Learning Object Proyect@ Matemáticas is presented in Fig. 4. 


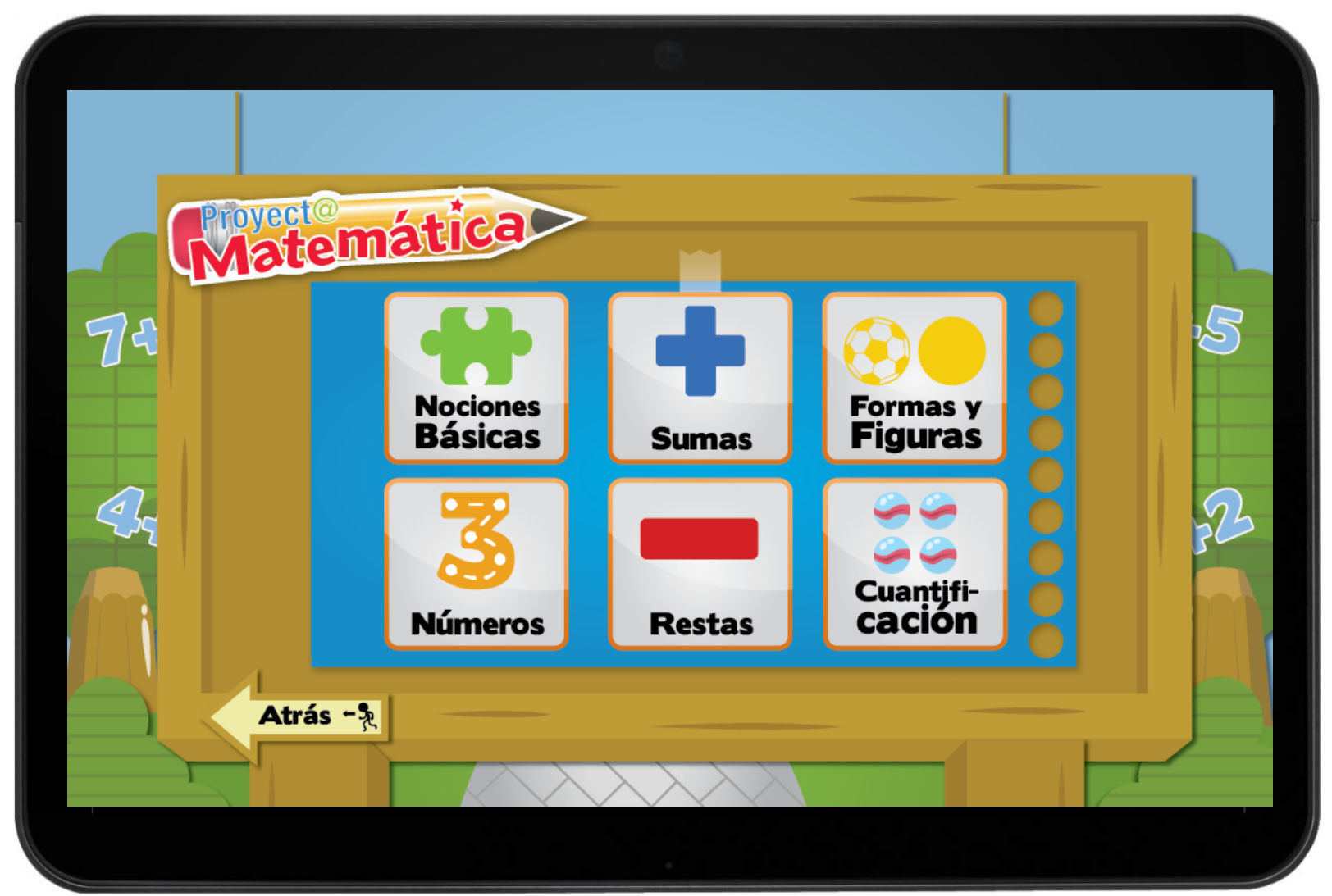

Figure 4: Pre-calculus interface of Proyect@ Matemáticas

The developed application focuses on level 3 of Chilean special education [30]. This regulation defines the five levels of activities to improve social and cognitive skills of children with ASD. A child is initially diagnosed at a specific level. Children diagnosed at level 1 are those with more critical special needs.

The LO Proyect@ Matemáticas allows work in two axes. The first is related to pre-calculus, in particular with:

- Basic notions: Correspondence, classification, seriation.

- Numbers: concept number (0 to 20), predecessor and successor, comparisons.

- Addition and subtraction: addition and subtraction operations.

- Relations between objects and number: quantification.

- Forms and figures: forms and shapes in 2D and 3D.

And the second with Functional Mathematics, which are applied to environment and the use of money in Chile:

- Learn about money: recognition of elements of the Chilean monetary system.

- Use of money: utilization of the monetary system for purchasing objects.

- Money management: generation of quantities within the monetary system.

- Everyday problems: contextualization of use of money in real life situations.

\section{Preliminary Validation}

For preliminary validation, expert evaluations and preliminary tests with users were conducted.

\subsection{Expert evaluations}

A group of 15 experts, after having used the application, were asked to respond to an instrument based on the study and evaluation of learning objects (Learning Object Evaluation Metric) [31]. This instrument assesses 4 points 
(Interactivity, Design, Engagement, and Usability), which were adapted to Proyect@ Matemáticas.

The experts who evaluated the application were distributed according to the following profiles: 7 speech pathologists, 6 special-education educators, and 2 occupational therapists. All of them had more than 3 years of experience working with ASD. It was hoped that in the evaluation, no point of the assessment would have a percentage greater than $50 \%$ in the deficient category.

Tables 2-5 present the results obtained in the areas of Interactivity, Design, Engagement, and Usability. An evaluation of an excellent rating corresponds to a very positive aspect, and one of poor rating will mean an aspect to be improved soon.

Table 2: Interactivity Results

\begin{tabular}{cccc}
\hline Interactivity & Excellent & Acceptable & Deficient \\
\hline Meaningful interactions & $80 \%$ & $20 \%$ & $0 \%$ \\
\hline Overall control & $87 \%$ & $7 \%$ & $7 \%$ \\
\hline Multimedia adds learning value & $87 \%$ & $13 \%$ & $0 \%$ \\
\hline
\end{tabular}

Table 3: Design Results

\begin{tabular}{cccc}
\hline Design & Excellent & Acceptable & Deficient \\
\hline Consistency & $93 \%$ & $7 \%$ & $0 \%$ \\
\hline Layout & $87 \%$ & $13 \%$ & $0 \%$ \\
\hline Labelling & $87 \%$ & $13 \%$ & $0 \%$ \\
\hline Readability & $100 \%$ & $0 \%$ & $0 \%$ \\
\hline
\end{tabular}

Table 4: Engagement Results

\begin{tabular}{cccc}
\hline Engagement & Excellent & Acceptable & Deficient \\
\hline Quality of feedback & $67 \%$ & $33 \%$ & $40 \%$ \\
\hline Attractive & $60 \%$ & $0 \%$ & $13 \%$ \\
\hline Graphics & $87 \%$ & $33 \%$ & $27 \%$ \\
\hline Amount of multimedia & $67 \%$ & $0 \%$ & $0 \%$ \\
\hline Motivating & $73 \%$ & $0 \%$ \\
\hline
\end{tabular}

Table 5: Usability Results

\begin{tabular}{cccc}
\hline Usability & Excellent & Acceptable & Deficient \\
\hline Natural to use & $80 \%$ & $33 \%$ & $0 \%$ \\
\hline Orientation & $67 \%$ & $40 \%$ & \\
\hline Navigational cues & $67 \%$ & $33 \%$ & $0 \%$ \\
\hline Instructions & $67 \%$ & $27 \%$ & $0 \%$ \\
\hline
\end{tabular}

Considering the criteria related to Interactivity, it is possible to mention that within the three evaluation points, this received a good approval by the professionals, the area best evaluated being the facet related to the "Multimedia adds learning" and "Overall control" indicating that in $87 \%$ of the queried experts believe that the interactions of the system are significant. This indicates that the application delivers significant interactions and learning which will allow children with ASD to work in the future with it.

In the evaluation for the Design criteria, it is possible to see that approval is encouraging, as none of the professionals scored a "poor" item of assessment. The item with the highest approval levels is related to the stages, which leads to conclude that an adequate design of levels was accomplished. They were not distributed in a disorganized manner and it can be understood perfectly what was intended to be transmitted through them.

As for items related to Engagement, they also obtained a very positive approval, as none of the professionals scored a poor item of assessment. The area best evaluated is related to Graphics provided by Proyect@ Matemáticas, reaching $87 \%$ of "excellent" level.

Good results were also obtained in the criteria related to Usability, as in all items at least $67 \%$ was obtained in the "excellent" level. The item best evaluated is related to the application being "Natural to use". This is very 
important, since the instructions should be explicit to prevent children from feeling disoriented when they perform the activities.

\subsection{Preliminary Test}

In order to obtain accurate data and a correct evaluation of the application, it is necessary to have perspective and context of use from the point of view of end-users of the application, this being the reason why such tests were carried out. With this technique of testing, it is possible to obtain data in quantitative and qualitative terms on the performance of participants. To obtain reliable data, ten random children of different ages and sex were selected, in order to contrast the average results with the results of the tests previously carried out with end users, specifically with children with ASD from Germina School [32].

Testing with end users was conducted on the premises of Germina School, where we used a Samsung Galaxy Tab tablet with the application installed, with a total of ten children who were between education levels 2 and 3 for ASD. More specifically, six children of level 2 and 4 children of level 3 worked with the application. It should be noted that respective permits were solicited before beginning the activity, so as to have informed parental consent (and the respective concurrence) and the authorization to make recordings of the activity.

It should be pointed out that the educational levels of autism for Chile are regulated by decree 815 and 170 of Special Education, which divides Special Education into four levels, which seeks to develop and work on the following behaviors [30], [33]:

- Level 1: Stimulate the emergence of basic adaptive behaviors in order to initiate the interaction of the person with his or her environment.

- Level 2: Strengthen adaptive behaviors that allow the person a better standard of living and greater interaction with his or her environment.

- Level 3: Develop abilities and skills that enable the learner to engage in standardizing environments.

- Level 4: Enable the acquisition of learning related to work life.

Finally, tests with users, in quantitative terms, were based on the points described in Tables 6 to 9 .

Table 6: Time used by users in order to complete a set of activities (Level 2)

\begin{tabular}{cccc}
\hline Activities & T $^{\mathbf{0}}$ Expected & Avg. & Std. Dev. \\
\hline Pre-calculus & $4,0 \mathrm{~min}$ & $4,5 \mathrm{~min}$ & 0.61 \\
\hline Functional mathematics & $4,0 \mathrm{~min}$ & $3,1 \mathrm{~min}$ & 0.63 \\
\hline
\end{tabular}

Table 7: Time used by users in order to complete a set of activities (Level 3)

\begin{tabular}{cccc}
\hline Activities & T$^{\mathbf{0}}$ Expected & Avg. & Std. Dev. \\
\hline Pre-calculus & $4,0 \mathrm{~min}$ & $4,3 \mathrm{~min}$ & 0.61 \\
\hline Functional mathematics & $4,0 \mathrm{~min}$ & $3,3 \mathrm{~min}$ & 1.51 \\
\hline
\end{tabular}

Table 8: Number of errors made per activity

\begin{tabular}{ccc}
\hline Activities & Level 2 & Level 3 \\
\hline Pre-calculus & 6 & 1 \\
\hline Functional mathematics & 11 & 2 \\
\hline
\end{tabular}

Table 9: Number of errors made per game

\begin{tabular}{|c|c|c|c|c|c|c|c|c|c|c|}
\hline \multirow{3}{*}{$N^{o}$ Errors Level 2} & \multicolumn{5}{|c|}{ Pre-calculus } & \multicolumn{5}{|c|}{ Functional Mathematics } \\
\hline & G1 & $G 2$ & G3 & G4 & G5 & G6 & $G 7$ & G8 & $G 9$ & $G 10$ \\
\hline & 2 & 0 & 1 & 3 & 0 & 0 & 2 & 3 & 3 & 3 \\
\hline$N^{o}$ Errors Level 3 & 0 & 0 & 0 & 1 & 0 & 0 & 0 & 0 & 0 & 2 \\
\hline
\end{tabular}


The level 3 students present better results in number games and a higher average time in comparison to level 2. A possible explanation is that level 3 are expected to having a higher development of mathematical skills, so that they made a more throughout analysis of the obtained math results. In contrast, level 2 students tend to only count objects, which generated a greater index of error.

The level 3 students possess better results in money games and a lower average time in comparison to level 2. This is due to level 2 students still not having studied money management content, which generated a great amount of error in every game that was related to mathematics involving coins and bills; in contrast, it is expected that level 3 students must have worked for some time with this topic.

The game with the most errors in the tests is the subtraction game in the pre-calculus topic. This is probably due to the complexity of the operation and the level of abstraction that is handled in such operations. This game was the most complicated for both levels, unlike with level 3 in which you could explain how to obtain an answer through the use of fingers. For these reasons, it is intended to make improvements to this game in terms of interaction with the various present elements.

In Figure 5, evidence of a child with ASD utilizing the LO Proyect@ Matemáticas is presented.

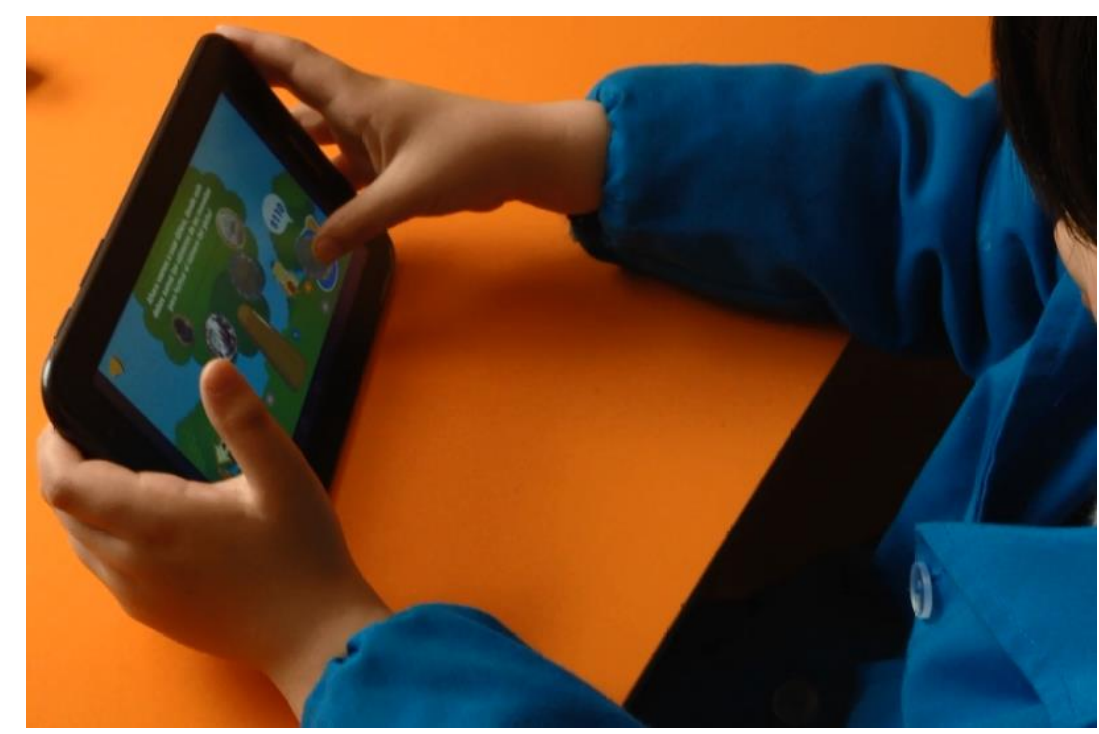

Figure 5: Children playing with LO Proyect@ Matemáticas

\section{IMPLANTATION}

The implantation was realized in the Google Play application store, with an account associated with the Universidad de Valparaíso. This same account is associated with the previously developed applications "Proyect@ Emociones" and "Proyect@ Habilidades".

After completing the process of implementation and complying with the regulatory norms of Google Play, the application is posted and ready for download from the store, as shown in the Figure 6. 


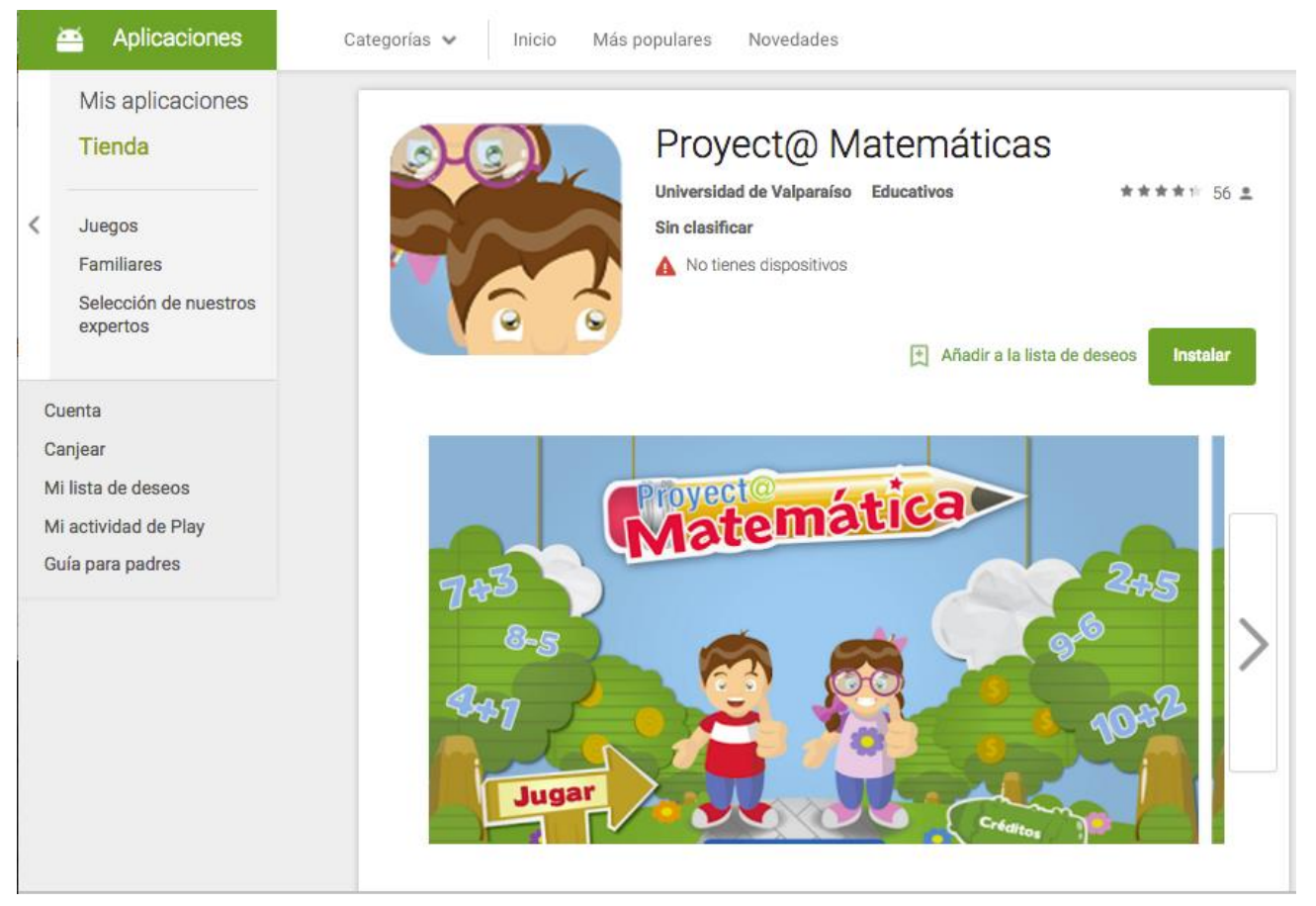

Figure 6: Proyect@ Matemáticas in Google Play

It is important to mention that once the application is published, new updates can be made, as it is the case in its current development cycle. Although the application has been developed considering the particularities of the Chilean context, it has been downloaded in more than five spanish-speaking countries. The main ones are: Chile (31.2\%), Spain $(23.20 \%)$ and Mexico $(14.1 \%)$.

On the other hand, the prevalent Android version for downloads is 4.4, with $41.5 \%$ of the donwloads, followed by Android 6.0 with $16.5 \%$. As a conclusion, the fact that the application had downloads from outside Chile brings clear evidence of a demand for applications that develop diminished skills in ASD.

\section{CONCLUSIONS AND Future WORK}

Autism spectrum disorders require a multidisciplinary approach based in technology for the development of critical cognitive skills for performance in a society that establishes entry barriers for neurodiversity. The Learning Object presented in this article aims to contribute in overcoming this challenge through a systematic approach centered on the user. In this sense, the development of functional mathematics skills addressed in the LO can make the difference between a person that depends on a third party for making purchases verses someone that can rely on his or her selfsufficiency in the use of money.

Learning objectives to be achieved by using the LO were defined with the support of a group of specialists, based on the Chilean regulations for special education. A design process centered on the user was conducted in order to understand necessary considerations so that the target public of the application could interact with it and fulfill the defined learning targets. The process was concluded with the evaluation on one part by a panel of 15 experts of distinct disciplinary areas that contributed to the improvement of the learning object. Finally, they validated its utility from the point of view of the developed content, learning strategies incorporated from local best practices in this area, interaction, design, usability and involvement potential of the user interface. The application was tested in 10 children diagnosed with ASD with distinct functioning levels, achieving successful results in terms of time and effectiveness in the completion of tasks, with reasonably different performances depending on skill development levels of users.

The application is currently available in the Google Play store, reaching more than 15,000 downloads and an average rating of 4.2 out of 5 points. It is worth mentioning that the few negative evaluations come from users with problems in installing the application, and are not related to functional problems or in difficulties to use the software.

Future work in developing the LO considers adding new activities that will extend the learning objectives beyond the current version. In this way, the approach used for the present development is reusable, such as several of the assets of the application and the learning strategies applied, which will permit the generation of new versions with better strength than the current version. On the other hand, a formal validation of the learning object in a larger 
population of users would permit the generation of evidence of its impact and considerations for effective inclusion in the process of development of math skills in children with ASD.

\section{Acknowledgements}

Roberto Muñoz is partially funded by the INF-PUCV 2015 doctoral scholarship grant. Rodolfo Villarroel is funded by the VRIEA-PUCV 2017 039.440/2017 grant. We would like to show our appreciation/gratitude to Sebastian Stek Larco for the invaluable support in the interface/interaction design. Finally, the authors would like to thank Travis Jones for his valuable contributions to the elaboration of this paper.

\section{References}

[1] L. Wing, The Autistic Spectrum. Ulysses Press, 2001.

[2] H. De Clercq and A. Van Lenteren, El autismo desde dentro: Una guía práctica. Kungsängen: Intermedia Books, 2006.

[3] T. Peeters, Autismo: De la comprensión teórica a la intervención educativa. San Diego, Calif: Singular Pub. Group, 1997.

[4] American Psychiatric Association, Diagnostic and Statistical Manual of Mental Disorders, 5th Edition: DSM 5. Washington, DC, USA, 2013.

[5] R. Munoz, T. Barcelos, R. Noel, and S. Kreisel, "Development of Software that Supports the Improvement of the Empathy in Children with Autism Spectrum Disorder," in Proceeding of the 31st International Conference of the Chilean Computer Science Society, Valparaíso, Chile, 2012, pp. 223-228.

[6] D. L. Christensen et al., "Prevalence and Characteristics of Autism Spectrum Disorder Among Children Aged 8 Years - Autism and Developmental Disabilities Monitoring Network, 11 Sites, United States, 2012," MMWR Surveill. Summ., vol. 65, no. 3, pp. 1-23, Apr. 2016.

[7] F. R. Volkmar, B. Reichow, and L. A. Wiesner, "Autism and Aspergers," in Encyclopedia of Adolescence, Elsevier, 2011, pp. 62-67.

[8] Ministerio de Educación, "Bases Curriculares Educación Básica - Año 2013,” 2013. [Online]. Available: http://educrea.cl/bases-curriculares-educacion-basica-ano-2013/. [Accessed: 29-May-2016].

[9] L. A. M. Zaina and A. Álvaro, "A design methodology for user-centered innovation in the software development area,” J. Syst. Softw., vol. 110, pp. 155-177, Dec. 2015.

[10] J. J. Garrett, The elements of user experience user-centered design for the Web and beyond. Berkeley, CA: New Riders, 2011.

[11] T. Lowdermilk, User-centered Design: A developer's guide to building user-friendly applications, First edition. Beijing: O’Reilly, 2013.

[12] A. Marcus, "User-Centered Design in the Enterprise," Interactions, vol. 12, no. 1, p. 18, Jan. 2005.

[13] R. Muñoz, T. Barcelos, S. Kreisel, M. Oróstica, R. Villarroel, and I. Frango, "Software de Apoyo al Desarrollo de la Función Ejecutiva en Niños con Trastornos del Espectro Autista," in Anais dos Workshops do IV Congresso Brasileiro de Informática na Educação, Maceio, Brasil, 2015, pp. 748-757.

[14] D. M. Blischak and R. W. Schlosser, "Use of Technology To Support Independent Spelling by Students with Autism," Top. Lang. Disord., vol. 23, no. 4, pp. 293-304, 2003.

[15] F. D. DiGennaro Reed, S. R. Hyman, and J. M. Hirst, "Applications of technology to teach social skills to children with autism," Res. Autism Spectr. Disord., vol. 5, no. 3, pp. 1003-1010, Jul. 2011.

[16] S. Bereznak, K. M. Ayres, L. C. Mechling, and J. L. Alexander, "Video Self-Prompting and Mobile Technology to Increase Daily Living and Vocational Independence for Students with Autism Spectrum Disorders," J. Dev. Phys. Disabil., vol. 24, no. 3, pp. 269-285, Jun. 2012.

[17] L. C. Mechling, D. L. Gast, and N. H. Seid, "Using a Personal Digital Assistant to Increase Independent Task Completion by Students with Autism Spectrum Disorder," J. Autism Dev. Disord., vol. 39, no. 10, pp. 14201434, Oct. 2009.

[18] J. P. Hourcade, S. R. Williams, E. A. Miller, K. E. Huebner, and L. J. Liang, "Evaluation of tablet apps to encourage social interaction in children with autism spectrum disorders," 2013, p. 3197.

[19] J. Wade et al., "A Gaze-Contingent Adaptive Virtual Reality Driving Environment for Intervention in Individuals with Autism Spectrum Disorders," ACM Trans. Interact. Intell. Syst., vol. 6, no. 1, pp. 1-23, Mar. 2016.

[20] IEEE Computer Society, “1484.12.1-2002 - IEEE Standard for Learning Object Metadata,” 2002.

[21] G. Herrera, X. Casas, J. Sevilla, L. Rosa, C. Pardo, J. Plaza, R. Jordan, and S. Le Groux, "Pictogram Room: Natural Interaction Technologies to Aid in the Development of Children with Autism," Annu. Clin. Health Psychol., vol. 8, no. 2012, pp. 39-44, 2012. 
[22] R. Munoz, C. Becerra, R. Noel, T. Barcelos, R. Villarroel, S. Kreisel, and M. Camblor, "Proyect@ matemáticas: A learning object for supporting the practitioners in autism spectrum disorders," in Proceedings of the XI Latin American Conference on Learning Objects and Technology, Costa Rica, 2016.

[23] M. Bonnin, R. Muñoz, "Metodología de Trabajo con Personas con TGD y sus Familias: Aplicación de Nuevas Tecnologías," 2010.

[24] "Ministerio de Educación de Chile - Mineduc." [Online]. Available: http://www.mineduc.cl/. [Accessed: $27-$ Mar-2013].

[25] T. Aydemir, "A Review of the Articles about TouchMath,” Procedia - Soc. Behav. Sci., vol. 174, pp. 18121819, Feb. 2015.

[26] M. Llinares, I. Plasencia, and P. Rodríguez, "Diagramas para la comprensión matemática. Un estudio de caso en personas con trastorno del espectro autista," Rev. Educ. Inclusiva, vol. 2, no. 1, pp. 79-90, 2009.

[27] I. Gulliksen, A. Lantz, "User Centered Design in Practice - Problems and Possibilities," 1999.

[28] D. van Dijk, F. Kresin, M. Reitenbach, E. Rennen, and S. Wildevuur, Users as Designers A hands-on approach to Creative Research. Waag Society, 2011.

[29] C. Snyder, Paper prototyping : the fast and easy way to design and refine user interfaces. San Francisco, CA: Morgan Kaufmann Publishers, 2003.

[30] "DTO-170 21-ABR-2010 MINISTERIO DE EDUCACIÓN - Ley Chile - Biblioteca del Congreso Nacional." [Online]. Available: http://www.leychile.cl/Navegar?idNorma=1012570. [Accessed: 19-Jun-2014].

[31] R. Kay and L. Knaack, "A multi-component model for assessing learning objects: The learning object evaluation metric (LOEM),” vol. 24, no. 5, pp. 574-591, 2008.

[32] Centro de Recursos Educativos GERMINA-, Bitácora del Centro de Recursos Educativos GERMINA- Quilpué - Chile, 2013. [Online]. Available: http://centrogermina.blogspot.com/.

[33] "DTO-815 07-OCT-1991 MINISTERIO DE EDUCACIÓN." [Online]. Available: http://www.leychile.cl/Navegar?idNorma=226792\&idParte=0. [Accessed: 09-Apr-2013]. 